\title{
Review: behavioural interventions plus laxatives are effective for defecation disorders in children, but biofeedback does not add benefit
}

Source of funding:

National Health Service.

For correspondence:

Ms M Brazzelli,

University of Aberdeen,

Aberdeen, UK

mgb@hsru.abdn.ac.uk

A modified version of this

abstract appears in

Evidence-Based

Medicine.
Brazzelli M, Griffiths P. Behavioural and cognitive interventions with or without other treatments for defaecation disorders in children. Cochrane Database Syst Rev 2001; (4):CD002240 (latest version 1 July 2001).

\author{
QUESTION: In children with defecation disorders, are behavioural interventions \\ effective?
}

\section{Data sources}

12 databases were searched in March 2001, reference lists were scanned, and experts were contacted.

\section{Study selection}

Unsuccessful rates for cognitive, behavioural, or cognitive and behavioural interventions for defecation disorders in children*

\begin{tabular}{lllll} 
Comparisons & Follow up & $\begin{array}{l}\text { Weighted } \\
\text { event rates }\end{array}$ & RRI (95\% Cl) & NNH (CI) \\
\hline Conv + biofeed $v$ conv & 12 months & $52 \% v 45 \%$ & $16 \%(-4$ to 40$)$ & Not significant \\
\cline { 2 - 5 } & 18 months & $52 \% v 46 \%$ & $15 \%(-11$ to 48$)$ & Not significant \\
\hline Biofeed + lax $v$ biofeed & 12 weeks & $91 \% v 56 \% \dagger$ & $63 \%(16$ to 149$)$ & 3 (2 to 10$)$ \\
\hline & 12 months & $91 \% v 64 \% \dagger$ & $43 \%(5$ to 108$)$ & 4 (3 to 28$)$ \\
\hline BM + lax $v$ BM & & & RRR (Cl) & NNT (CI) \\
\hline BM + lax $v$ lax & Not months & $43 \% v 60 \%$ & $28 \%(5$ to 46$)$ & 6 (4 to 28$)$ \\
\hline
\end{tabular}

${ }^{*}$ Biofeed $=$ biofeedback; $\mathrm{BM}=$ behavioural modifications; conv = conventional treatment (laxatives, dietary advice, and toilet training); lax = laxatives. Other abbreviations defined in glossary; RRI, RRR, NNH, NNT, and Cl calcuand toilet training); lax

lated from data in article.

\section{COMMENTARY}

The systematic review by Brazzelli and Griffiths examines the effectiveness of behavioural interventions for defecation problems and encopresis in children. A thorough database search produced only 12 randomised controlled trials that were available for review. The review was limited by differences among the studies on salient variables including causal factors (behavioural, neurological, and constipation), mean age (6-12 y), intervention (eg, toilet training, scheduling, biofeedback, and laxatives), intervention duration (12 d to 6 mo), number and duration of follow up assessments (0-3 times), and outcomes (soiling, bowel movements in toilet, anorectal pressures, and number of children improved). Loss to follow up and study heterogeneity limited data combination and, consequently, any firm conclusions about the benefits of a particular intervention. Most studies, however, indicate that behavioural treatments in combination with laxatives are more effective than either intervention alone.

This review underscores the need for educational interventions for parents and children to prevent constipation that may precede encopresis. Parenting practices around diet and toilet training are strong determinants of healthy bowel function in children. ${ }^{1}$ Nurses in multiple settings are well situated to enable parents to promote healthy bowel practices at each stage of child development. Nurses can provide anticipatory guidance, using the Canadian Pediatric Society Guidelines on toilet training,, on appropriate fluid intake, introduction of solids, and the role of dietary fibre.

Loretta Secco, RN, PhD Assistant Professor, Faculty of Nursing University of Manitoba Winnipeg, Manitoba, Canada

1 Baker SS, Liptak GS, Colletti RB, et al. Constipation in infants and children: evaluation and treatment. A medical position statement of the North American Society for Pediatric Gastroenterology and Nutrition. J Pediatr Gastroenterol Nutr 1999;29:612-26. http:// www.naspghan.org/PDF/constipation.pdf

2 Canadian Pediatric Society. Toilet learning: anticipatory guidance with a child-oriented approach. Paediatrics and Child Health 2000;5:333-5. http://www.cps.ca/english/ statements/CP/cp00-02.htm

Randomised or quasi-randomised controlled trials of cognitive, behavioural, or cognitive and behavioural interventions in children with a history of faecal soiling with and without constipation were included.

\section{Data extraction}

Data were extracted on participant characteristics, interventions, outcomes (including number of unsuccessful children [not cured or improved]), and study quality.

\section{Main results}

14 studies (12 randomised controlled trials, 843 children) met the selection criteria. Children had encopresis in 12 studies and faecal incontinence resulting from congenital abnormalities in 2 studies. Study duration was 2-6 weeks in 6 studies, $8-18$ weeks in 6 studies, and 12 months in 1 study. 8 studies compared conventional treatment (laxatives, dietary advice, and toilet training) plus biofeedback with conventional treatment alone. The groups did not differ for number of "unsuccessful" children at 12 and 18 months (table). 1 study compared biofeedback training plus laxatives with biofeedback alone. More children in the biofeedback plus laxatives group than in the biofeedback alone group were unsuccessful at 12 weeks and 12 months (table). 2 studies compared behaviour modifications (toilet training, rewards, and counselling or dietary advice) plus laxatives with behaviour modifications alone. The laxative group had fewer unsuccessful children than did the behaviour modifications alone group at 6 and 12 months (table). 1 study comparing diet modifications and scheduled toileting with mineral oil alone did not differ on any outcomes. 1 study comparing behaviour modifications plus psychotherapy with behaviour modifications alone showed similar findings in each group. 1 study compared 3 groups: behaviour modifications (incentive programmes, toilet training) plus laxatives, laxatives alone, and biofeedback. Behaviour modifications plus laxatives were better than laxatives alone for reducing the number of unsuccessful children (table).

\section{Conclusions}

In children with defecation disorders, biofeedback does not add benefit to conventional treatment. The combination of behavioural modification techniques and laxatives is more effective than either intervention alone. 